\title{
CORDEL BRASILEIRO: MATERIALIDADES DA VOZ E DO CORPO EM PERFORMANCE
}

\author{
Brazilian Cordel: voice's and body materialities in performance \\ Cordel brasileño: Materialidades de voz y de cuerpo en performance \\ Maria Gislene Carvalho Fonseca \\ Professora do Departamento de Jornalismo e do Programa de Pós-Graduação em \\ Comunicação Social da UFOP \\ gisacarvalho@ufop.edu.br
}

Resumo: Este trabalho é uma reflexão teórica sobre os traços de oralidade que caracterizam a poesia de cordel, suas narrativas e performances. Esta discussão está apoiada em Ong (1990), sobre oralidade, e Zumthor (2014) em torno da ideia de performance. Ambos nos conduzem à ideia da produção da presença de Gumbrecht (2010), trabalhada aqui no caso dos improvisos poéticos. Percebemos que a poesia de cordel transcende a existência em um único suporte e se manifesta como uma textualidade, cujas definições - abertas - estão situadas nos processos das memórias, tradições e das relações que emergem no texto em ação.

Palavras-chave: Cordel; Performance; Oralidade.

Abstract: This paper is theoretical reflection about orality in Cordel poetry, their narratives and their performance. We are suported by Ong (1990), about orality, and by Zumthor (2014) about performance. Both lead us to the ideology of Gumbrecht's production of presence (2010), working here as a kind of poetic improvisations. We realize that cordel poetry transcends the existence in one support and manifests itself as a textuality, whose definitions open - are located in the processes of memories, traditions and relationships that emerge in action of the text.

Key-words: Cordel; Perfomance; Orality.

Resumen: Este trabajo es una reflexión teórica sobre los rasgos de oralidad que caracterizan a la poesía de cordel, sus narraciones y performances. Esta discusión es apoyada por Ong (1990), sobre oralidad, y Zumthor (2014) en torno a la idea de performance. Ambos nos llevan a la ideología de la producción presencia de Gumbrecht (2010), trabajada aquí como improvisaciones poéticas. Nos damos cuenta de que la poesía de cordel trasciende la existencia en un soporte y se manifiesta como una textualidad, cuyas definiciones, abiertas, se ubican en los procesos de recuerdos, tradiciones y relaciones que surgen en el texto em acción.

Palavras-clave: Cordel; Performance; Oralidad. 


\section{INTRODUÇÃO}

A proposta deste trabalho é realizar uma discussão teórica em torno da materialidade poética do cordel, que passa pela voz, e se manifesta no corpo em performance. Para isso, tenho como embasamento as discussões realizadas a partir de Ong (1990) e de Zumthor (2014), com reflexões sobre a oralidade como ponto de partida, mas que se manifestam também impressas e online. Buscamos compreensões da poesia de cordel a partir destas referências sobre oralidade e performance.

Propomos um olhar que, pelas vias da performance, possibilitam o reconhecimento da poesia de cordel como uma obra, que não está situada apenas no conjunto de enunciados, mas em uma textualidade (LEAL, 2016) que articula elementos como poetas, públicos, ambientes, temporalidades, memórias, tradições.

A referência de recorte sobre um cordel "brasileiro" justifica-se pelas outras formas identificadas de cordéis em outros lugares do mundo, como é o caso dos folhetos encontrados em Portugal e na Espanha. Estes cordéis não são apresentados na forma de poesia, tampouco passam pela oralidade, sendo vendidos os folhetos que contam narrativas ficcionais em prosa, conforme nos apresenta Abreu (1993), para quem o cordel brasileiro, sobre o qual tratamos aqui, é uma manifestação poética específica do Nordeste do Brasil.

Não significa que não haja contribuições e diálogos entre eles, como é o caso da forma do folheto e dos modos de venda em bancas e feiras. Mas é que o cordel que conhecemos hoje, já surge na forma de poesia e é um híbrido da escrita e impressão, adquirida com a chegada das máquinas impressoras ao interior do País, com a poesia oral cantada pelos violeiros que levavam as novidades de feira em feira, de cidade em cidade.

Como discussão teórica que nos encaminha a uma compreensão do cordel como fenômeno múltiplo, vivo, pulsante, contraditório, aqui não realizamos uma análise empírica sobre folhetos específicos. Tampouco unificamos a ideia do cordel em uma definição fechada. A reflexão aqui desenvolvida aponta para nossa tentativa de abrir a ideia do cordel para além das formas, estruturas e suportes, considerando que o cordel é, como aponta Carvalho (2002, p. 287), "uma iluminação (epifania), um instante mágico de viver esta emoção que a voz transmite, do corpo que fala no gesto e na performance, da leitura individual ou coletiva de um folheto", e que se reconhece também nas xilogravuras, na cantoria, no improviso, nas imagens de Nordeste(s) do Brasil. 


\section{A TEXTUALIDADE DO CORDEL}

O texto em ação é uma performance, um processo, que diz de um uso social dos signos, cujos sentidos se modificam a partir de cada tessitura narrativa, dizem dos lugares sociais que os indivíduos participantes do texto ocupam na eventualidade da enunciação e, como tal, fazem referência a uma série de outras ações, tomadas também como textos.

$\mathrm{Na}$ verdade, performance oferece um enquadre que convida à reflexão crítica sobre os processos comunicativos. Uma dada performance está ligada a vários eventos de fala que a procedem e sucedem (performances passadas, leituras de textos, negociações, ensaios, fofoca, relatos, críticas, desafios, performances subsequentes, e similares). (BAUMAN e BRIGGS, 2006, p. 189)

Deste modo, entendemos o cordel como uma textualidade, a partir da reflexão de Leal (2018), que entende o texto como um processo complexo, cujas demarcações estão situadas nas ações dos indivíduos que o constituem. Assim, para o pesquisador, "a textualidade faz com que os textos não sejam artefatos estáveis, mas, sim, amálgamas provisórios de relações em curso." (LEAL, 2018, p. 25). Deste modo, entender a textualidade implica questionarmos os contornos e limites decisivos para as relações investigadas que, neste texto, buscamos a partir das diversas materialidades que compõem o cordel.

Assim, no caso específico do cordel, como um texto que se manifesta em performance - seja na declamação, no improviso ou na leitura - temos um conjunto de relações que acontecem em cada leitura/audição. As tessituras dos sentidos que emergem na poesia nos dizem de um fenômeno comunicacional que articula atores, cenários, temporalidades, formas, suportes, memórias a cada enunciado. Como performance, cada texto é único.

Para compreender a ideia de performance, Zumthor (2014, p. 34-35) a define como um saber-ser que implica uma presença e uma conduta com coordenadas espaçotemporais encarnadas em um corpo vivo. Zumthor fundamenta seu conceito de performance a partir de quatro traços propostos por Dell Hymes: 1. A performance faz passar algo do virtual ao real; 2. Está situada em um contexto cultural e situacional, aparecendo como uma emergência; 3. É uma conduta na qual o sujeito assume responsabilidade e 4. A performance modifica o conhecimento.

Para Zumthor (1993), captar a performance significa captar uma ação, percebendo o texto que é realizado por ela, ou seja, o texto que emerge, que se torna real ao ser performance. Assim, o texto para Zumthor (1993, p. 220) é uma "sequência linguística que 
tende ao fechamento, e tal que o sentido global não é redutível à soma dos efeitos de sentidos particulares produzidos por seus diversos componentes", do qual a voz em performance extrai a obra. Esta, por sua vez, pode ser compreendida como o que entendemos como textualidade, ou ainda a totalidade dos elementos que compõem uma performance, um texto em ação.

Ao tomarmos o texto em movimento, no momento em que ele emerge e se materializa em comunicação, temos uma performance. Segundo Zumthor (1993), a obra performatizada é por natureza um diálogo, uma troca na qual a existência de um público é fundamental. “A comunicação oral não pode ser monólogo puro: ela requer imperiosamente um interlocutor, mesmo se reduzido a um papel silencioso" (ZUMTHOR, 1993, p. 222), porque é na relação que ela se constitui.

A poesia de cordel, que aparece escrita, impressa em folhetos, também é declamada oralmente. Essa declamação é performada, articulando vozes e corpos de poetas e públicos, construindo uma situação comunicativa em presença. "A performance é o único modo vivo da comunicação poética" (ZUMTHOR, 2014, p. 37) e que se manifesta a partir da presença demarcada em suas materialidades.

A performance pode ser considerada também em textos impressos, se pensamos na ideia do texto na ação da leitura, cuja produção da presença de poetas e públicos se estabelece mediada pela matéria do impresso durante as leituras individuais. Já ao referirmonos ao improviso e às declamações ao vivo de versos, temos em um mesmo momento os instantes da criação, transmissão e leitura de uma obra. A presença se realiza no mesmo cenário e tempo, possibilitando o "compartilhamento de sensações, sentimentos, afetos e/ou mesmo na própria condição de estarmos juntos" (LEAL, 2018, p. 27).

Assim, a ideia de produção da presença diz de uma realização compartilhada, de uma simultaneidade, instantaneidade da comunicação, como aponta Gumbrecht (2010) sobre a poesia medieval - que guarda semelhanças com a poesia oral nordestina - e que tem a ver com um contato físico entre os atores participantes do evento comunicacional. Pelos aspectos relacionados à temporalidade, a presença é o tempo percebido como presente compartilhado em uma mesma ambientação.

Com relação à articulação temporal implícita nas mediações simbólicas, Ricoeur (2010) sugere um triplo presente: presente do passado, presente do presente e presente do futuro. O tempo presente é uma potencialidade que acontece na efemeridade do presente e da presença, ou da ideia de um presente em comum. A narrativa é a articulação prática dessa 
temporalidade, é o "tornar presente", inclusive aquilo que está ausente - que constitui uma das definições de memória.

Para Ricoeur (2010), a narrativa é uma forma de apreensão do tempo. O tempo que, na performance, também é definidor. As narrativas que emergem no improviso têm relações temporais que também atravessam todo o círculo mimético. Trata-se da organização de um tempo realizada em um tempo 'imediato', o do improviso, que conforma outro tempo para os públicos. O imediato está relacionado ao presente como o instante que deixa de ser quando se realiza, tornando-se passado. Mas, em presença, são tempos compartilhados pelos atores que fazem parte da performance.

A performance é o momento em que o texto acontece, em que ele é ação. Seja impresso, declamado ou cantado. É o momento em que o texto emerge na relação entre indivíduos que negociam referências e sentidos, a partir da simbolização significada pela voz. Para Zumthor (2010), a performance põe atores em presença e os meios em jogo, considerando como "circunstancia" as especificidades de tempo e de lugar.

$\mathrm{Na}$ forma oral, a performance é instantânea. A presença é física. Junta cenários, poetas e públicos em um mesmo ambiente e momento comunicacional. É o momento em que o texto emerge e constrói a obra. É uma interação imediata, que não depende de esperas ou de mídias que possibilitem "a mobilidade e temporal da mensagem” (ZUMTHOR, 2010, p. 27), que aumenta a distância entre produção e consumo. Distância que é quase apagada no momento da performance oral.

Para compreender uma performance, não podemos segregar os seus elementos constituidores, porque, assim como os indivíduos participantes instituem a performance, o texto também institui os indivíduos, ao se integrar a seu repertório. A definição de Zumthor (2010) nos permite articular os indivíduos e elementos constitutivos da performance como estratégia comunicacional:

A performance é a ação complexa pela qual uma mensagem poética é simultaneamente aqui e agora, transmitida e percebida. Locutor, destinatário, circunstâncias (quer o texto, por outra via, com a ajuda de meios linguísticos as represente ou não) se encontram concretamente confrontados, indiscutíveis. Na performance se redefinem os eixos da comunicação social: o que junta o locutor ao autor; e aquele em que se unem a situação e a tradição. (ZUMTHOR, 2010, p. 31)

A performance é a emergência de sentidos que são emitidos e percebidos. Estes sentidos são realizados pelos corpos, sendo importante considerá-los conceitual e metodologicamente, porque são os corpos físicos que entram em presença. Os corpos fazem 
emergir os textos. Realizam-nos em escritura ou na voz. Os textos dependem dos corpos para existirem. Como materialidades, são parte dos sentidos e das interpretações possíveis. São elementos fundamentais das performances.

Zumthor (2014) define o corpo como

o peso sentido na experiência que faço dos textos. Meu corpo é a materialização daquilo que me é próprio, realidade vivida e que determina minha relação com o mundo. Dotado de uma significação incomparável, ele existe à imagem do meu ser; é ele que eu possuo e eu sou, para o melhor e o pior. Conjunto de tecidos e órgãos, suporte da vida psíquica, sofrendo também as pressões do social, do institucional, do jurídico, os quais, sem dúvida, pervertem nele seu impulso primeiro. Eu me esforço, menos para apreendê-lo do que para escutá-lo, no nível do texto, da percepção cotidiana, ao som dos seus apetites, de suas penas e alegrias. (ZUMTHOR, 2014, p. 27)

Segundo Zumthor (2014), a definição de uma comunicação como poética depende da atividade do corpo e dos efeitos possíveis, dos sentimentos particulares, dos indivíduos e de suas maneiras "de existir no espaço e no tempo e que ouve, vê, respira, abre-se aos perfumes, aos tatos das coisas" (p. 38). O corpo sente a poesia e a transmite, considerando que a performance também está na dimensão do gestual.

Por isso, para entender o cordel e suas diversas materialidades, faz-se necessário, para o estudo do que Zumthor $(2014,2010)$ chama de obra, uma compreensão dos corpos que existem como relações, que pulsam, que ritualizam, que cantam, que dançam, que performam. É pelo corpo que a performance está ligada ao espaço. É com ele que a performance emerge e constrói narrativas. O corpo detém a voz e o ouvir, é o que materializa a comunicação poética oral.

O corpo é o que caracteriza a presença da performance. Corpos em presença de textos. Gestos que partem dos corpos e que compõem os processos de textualidades. Estabelecem contatos entre si e com os ambientes em que acontecem as performances. Corpos de poetas, corpos de públicos, corpo da pesquisadora, que é também afetada pela dimensão sensível que emerge das feiras e que também performa comportamentos e modos de observação.

Os corpos de poetas em improviso são presenças que demandam também outros corpos presentes, os corpos dos públicos, com quem estabelecem interações. São também corpos que passam e não param, mas ainda assim escutam - considerando que o sentido da audição é involuntário. Os corpos que são as vozes e os ouvidos. Corpos que tocam viola, corpos que vestem figurinos. Corpos que bem água e consomem nas feiras. Corpos que 
sentam, que saem, corpos que choram e riem. Os corpos que estão juntos no momento do improviso.

Os sentidos dos corpos nos levam a ideia da obra, que, segundo Zumthor (2014, 2010), como já mencionado, é composta pelos múltiplos elementos significantes que atribuem sentido ao texto, "tudo o que é poeticamente comunicado" (ZUMTHOR, 2014, p. 73). Por isso, entendemos que as performances se realizam não apenas nos poetas, mas também no público. Por isso, interessa-nos a textualidade cordel como os processos que colocam esses atores em relação.

Além dos corpos dos poetas em performance, os corpos leitores, de ouvintes e de transeuntes que compõem os cenários das feiras são importantes em um processo de efeitos sensoriais. "O texto poético significa o mundo. É pelo corpo que o sentido é aí percebido" (ZUMTHOR, 2014, p. 75). Corpos que tocam o mundo e por ele são tocados. E que se tocam entre si a partir das performances. São corpos que transitam, que escutam as cantorias, que compram nas feiras, que comem, que ativam todos os sentidos e os processos de cognição.

Os poetas, segundo Zumthor (2010), podem assumir vários papéis, desde a composição até a declamação dos poemas. Questões referentes a autoria não serão tratadas aqui, porque, no contexto da poesia, a autoria pode trazer uma série de questões, que não cabem no espaço deste artigo, visto que não podemos pensar que a autor-idade de um texto está situada integralmente na figura que compõe o poema. Mas compreendemos que intérpretes e públicos são fundamentalmente produtores de sentidos, significados e referências em um texto, a partir da compreensão da textualidade como um processo. E no caso da performance, a obra emerge das relações entre atores, tempos e cenários.

O lugar da emissão é ocupado pelo que venho chamando até aqui de poetas. Eles são compositores, cantadores, improvisadores, repentistas, escritores. Os ouvintes são o público. Chamo de ouvintes as pessoas que, intencionalmente, param para escutar as declamações. As outras pessoas que escutam as declamações enquanto transitam pelas feiras, chamo de transeuntes. Para Zumthor (2010), os ouvintes são partes das performances e tão importantes quanto os intérpretes, porque a recepção da poesia é um ato único, fugaz e individual. Dois ouvintes, ainda que estejam no mesmo momento, no mesmo lugar assistindo à mesma performance, são indivíduos diferentes, com experiências diversas e, portanto, com várias possibilidades de interpretações.

Como público da performance, os ouvintes são considerados coautores da obra. Porque a modificam e a significam a partir de suas próprias experiências. E porque interferem 
no poema declamado pelos intérpretes. É o movimento do círculo mimético das narrativas, que serão abordados mais adiante, em que o indivíduo reconfigura a narrativa, reconstruindoa para sua própria compreensão e para a transmissão. A interferência do público pode se dar também na interferência dos ouvintes no texto declamado pelos intérpretes. Há a possibilidade de adaptação, pois, na declamação ao vivo, a partir das reações percebidas nos ouvintes, intérpretes podem modificar suas declamações, modulando vozes e gestos pelas reações dos ouvintes.

\section{ORALIDADE: A VOZ DO CORDEL EM PERFORMANCE}

Para Zumthor (2010), a performance impõe ao texto um referente que é da ordem do corpo, ou seja, "é pelo corpo que nós somos tempo e lugar" (p. 166). Além da encenação que é parte da declamação, o corpo é percebido também pela presença da voz na poesia. Além da cognição do improviso, a materialidade da voz é fundamental para a compreensão da poesia de cordel, porque trata-se de uma poesia cuja forma é elaborada para ser cantada (a sextilha, por exemplo, é testada no ritmo de Ciranda, Cirandinha).

Deste modo, todas as formas em que o cordel brasileiro se apresenta derivam de uma estrutura poética oral, conforme indica Abreu (1993). Essa estrutura vem de uma prática de declamações de poetas, cantadores e violeiros, responsáveis por atualizar as novidades em cada cidade por onde passavam no Nordeste brasileiro até o início do século XX. Por isso, até hoje é impossível pensar nas materialidades do cordel sem considerar a dimensão oral que perpassa seja qual for o suporte em que ela se apresente.

Com o entendimento de uma oralidade que não é fixa, e em vez disso está totalmente associada às práticas socioculturais que a constituem e que são por elas constituídas, Walter Ong (1990) nos ajuda a compreender o poder determinante que os suportes assumem diante dos atos comunicativos. As formas orais não estão restritas apenas à transmissão de mensagens diversas, mas são partes de processos cognitivos e formas culturais de grupos sociais que têm nessa materialidade seus modos de transmissão tradicionais.

Ong (1990) nos leva a pensar sobre níveis de oralidade, pois há comunidades que não reconhecem a escrita como forma de registro e de comunicação. "Atualmente, centenas de línguas em uso ativo nunca foram escritas: nenhuma tem um modo efetivo de escrita. A oralidade básica da linguagem é permanente"1 (ONG, 1990, p. 7). Ele explica que é muito

\footnotetext{
1 "Even now hundreds of languages in active use are never written at all: no one has worked out an effective way to write them. The basic orality of language is permanent”. (ONG, 1990, p. 7)
} 
difícil para pessoas cujas formações acontecem em culturas letradas entenderem como se dá o pensamento que se abstém das imagens das palavras escritas, por exemplo, e observarem essas outras formas de comunicabilidade e de transmissão de saberes exclusivamente orais.

Os estudos sobre oralidade, segundo Ong (1990), são escassos. Porque o modo formal de estudos, de ensino e o conhecimento canônico passam pela escrita como forma de registro e de transmissão. Há uma espécie de hierarquização em setores da cultura escrita que menosprezam as formas orais de transmissão de conhecimento, algumas vezes invalidando o conhecimento produzido nesta materialidade. Para Ong (1990, p. 10), esse foco dos estudos nas culturas escritas - e mesmo na transcrição da oralidade para que se possa estudá-la - tem consequências ideológicas, que implicam em uma desvalorização do conhecimento compartilhado oralmente.

Deste modo, o estudo da oralidade do cordel, nosso caso, demanda uma reflexão conceitual e um procedimento metodológico que considere as especificidades de uma produção que não é necessariamente escrita. Pode vir a ser, mas no caso do improviso, dificilmente será transcrito. Se ele não foi memorizado, sua efemeridade faz com que se perca de registros. Daí, novamente, a importância da presença. O improviso acontece no presente.

Metodologicamente, como produção oral, entender os sentidos que se manifestam no cordel passa por diversos movimentos que a escrita, sozinha, não alcançaria identificar. Como a questão das tradições, das memórias. Os cenários que também são parte dos diálogos e dos sentidos. As relações com os públicos que são coautores, os comportamentos, as vestimentas que geram as ideias para os versos, os motes propostos que têm a ver com a situação vivida naqueles momentos de declamação. Ler um folheto impresso não nos permite experienciar essas situações. Assim como gravações também não. Estas ainda permitiriam identificar algumas poucas emoções, entonações, mas não nos trazem os ambientes. Já os vídeos nos mostram os ambientes, mas o fazem com recortes de enquadramento que podem deixar de fora elementos analíticos importantes. Deste modo, para estudos da oralidade no presente $^{2}$, a imersão no ambiente é fundamental - ainda que isso implique em mais uma transformação na performance que é a da presença de um pesquisador.

As sociedades que não utilizam formas escritas ou impressas, essas que nós letrados não conseguimos sequer imaginar como funcionam seus processos cognitivos, estão, segundo Ong (1990), situados no que ele chama de oralidade primária.

\footnotetext{
2 Não é impossível realizar estudos sobre a oralidade no passado. Mas devemos considerar as limitações causadas os equipamentos técnicos de registro.
} 
Como observado anteriormente, designo como "oralidade primária" a oralidade de uma cultura totalmente desprovida de qualquer conhecimento da escrita ou da impressão. É "primária" por oposição à "oralidade secundária" da atual cultura de alta tecnologia, na qual uma nova oralidade é alimentada pelo telefone, pelo rádio, pela televisão ou por outros dispositivos eletrônicos, cuja existência e funcionamento dependem da escrita e da impressão. Atualmente, a cultura oral primária, no sentido restrito, praticamente não existe, uma vez que todas as culturas sem conhecimento da escrita sofreram alguns de seus efeitos. Contudo, em diferentes graus, muitas culturas e subculturas, até mesmo num meio de alta tecnologia, preservam muito da estrutura mental da oralidade primária. ${ }^{3}$ (ONG, 1990, p. 11)

A transição entre as fases da oralidade acontece, segundo Ong (1990), envolvendo questões sociais, políticas, econômicas, culturais, religiosas e relacionadas a outras estruturas. Isso porque tais modificações que alcançam as formas de comunicação e de produção e transmissão de conhecimento repercutem em várias áreas da vida social e individual. As formas corporais, impressas, digitais e online de diálogos entram nas rotinas das pessoas e transformam o mundo e sua compreensão. Por isso é tão importante considerarmos, no contexto da oralidade, não apenas a voz em si, mas as implicações socioculturais que emergem dela.

No caso da poesia de cordel, temos uma situação de oralidade secundária, ou mista. Primeiro porque poetas estão inseridos em culturas letradas, em que a escrita e os processos de leitura são referências materiais dos processos de aprendizagem e de registros formais. Mas também porque a própria produção da poesia coloca em diálogo e complementaridade a escrita e a oralidade (da performance à venda de folhetos impressos).

Isso tem uma relação direta com as questões de conceituação teórica e mercadológicas do cordel, apresentadas em Fonseca (2019). O cordel, como um fenômeno fluido, não consegue ser apreendido em um formato, apenas, mas transita por diversos espaços, de acordo com as tecnologias disponíveis e com as demandas de consumo. Deste modo, o cordel transforma-se constantemente e alcança novos suportes e materialidades. A poesia de cordel se manifesta em diversos espaços e não pode ser encerrada em uma forma única.

\footnotetext{
3 "As noted above, I style the orality of a culture totally untouched by any knowledge of writing or print, "primary orality". It is "primary" by contrast with the "secondary orality" of present-day high-technology culture, in which a new orality is sustained by telephone, radio, television, and other electronic devices that depend for their existence and functioning on writing and print. Today primary oral culture is strict sense hardly exists, since every culture knows of writing and has some experience of this effects. Still, to varying degrees many cultures and subcultures, even in a high-technology ambiance, preserve much of the mind-set of primary orality." (ONG, 1990, p. 11)
} 
Observamos, então, que o processo de criação poética do cordel pode ser realizado integralmente na memória, como fazia Patativa do Assaré, segundo entrevista dada a Carvalho (2002a). Patativa dizia que os exercícios de criação e memorização eram "feitos na mente", podendo, depois, serem passados ao papel. Ainda assim, em algum momento convoca-se a escrita. Há também poetas que criam direto no papel, escrevendo os versos para a contagem silábica e a memorização das estrofes, que é posterior à escrita. Outros compõem direto em aplicativos digitais, salvando em nuvens online, compartilham em redes sociais. Esses modos de produção indicam que o cordel não está parado no tempo e que ele incorpora os usos e as transformações tecnológicas em sua produção. E é fundamental reconhecermos as especificidades técnicas e materiais, sem que com isso geremos uma dimensão de hierarquização das formas - mesmo entendendo que há disputas simbólicas entre as atuações em cada meio.

No caso da poesia de cordel produzida contemporaneamente, a questão dos suportes não é definidora do que será ou não considerado cordel, ainda que implique em seus sentidos possíveis, nas referências ideológicas que o englobam. A oralidade é fundamental para o conceito e para as questões formais de métrica, rima e ritmo. Mas a forma escrita também é muito importante. E a impressão não pressupõe apenas o folheto, mas há também livros de maior volume e que são editados por empresas maiores, vendidos em grandes livrarias - como as edições do Armazém da Cultura, da editora Imeph e, mais recentemente, da editora Seguinte.

No mercado editorial, por exemplo, encontramos obras de cordel em livros impressos, audiolivros e e-books. Nesse último formato, podemos mencionar casos em que há deslocamento da forma escrita consagrada em definições mais convencionais - seja por acidente de edição ou impossibilidade técnica de mantê-la - com o desarranjo da estrutura dos versos do texto poético na tela dos computadores, smartphones e tablets, o que gera consequências para a experiência de leitura. No entanto, não é um erro de edição em si o responsável por esse "deslocamento". Isso acontece, na verdade, em decorrência da própria textualidade assumida pelo cordel em outros dispositivos, ainda que fosse uma edição digital sem problemas ou erros. (CARVALHO, BARBOSA, MULLER, 2020, p.180)

Outra situação em que observamos esse trânsito de materialidades que compõem o entendimento do cordel está nos livros de Jarid Arraes - que ministra oficinas de cordel e cujo modo de criação é escrito, ainda que convoque movimentos de oralidade o tempo inteiro para testar a forma da poesia. Os versos de Jarid são impressos em folhetos, mas também 
editados em livros ${ }^{4}$ que são vendidos em livrarias e pela Internet. Internet que também faz circular essa poesia, estendendo a ideia da presença, que, neste caso, dispensa a simultaneidade do espaço físico, configurando-se uma "presença virtual”. Mas isso não é o tema aqui, e essa discussão pressupõe um embasamento teórico mais aprofundado sobre as questões da Internet. O que quero apontar é que a poesia de cordel, ainda que apresentada impressa ou digital, em declamações na televisão ${ }^{5}$ ou no Youtube $^{6}$, guarda os traços da oralidade na forma. Como um texto audio-verbo-visual (ABRIL, 2014).

No caso do improviso, a criação não dispõe de tempo para a escrita. Mas os treinos, exercícios, o trabalho de organização de rimas feito antes de começar a declamação podem passar também pela escrita. Já o momento em que a performance acontece prescinde da utilização de papéis, de anotações ou de textos impressos para a declamação. Há também os formatos de declamação que consistem na leitura de folhetos para um determinado público. Mas estes não apareceram nos eventos das feiras que acompanhei.

Neste caso, entendemos os apontamentos de Zumthor (2010) sobre a memória referir-se não a um texto, mas às normas do gênero trabalhado. $\mathrm{O}$ improvisador organiza materiais "brutos": temas, palavras, expressões, cenas, motes, juntando na cantoria elementos de outras atividades de memorização, que são trazidos à declamação do momento. Deste modo, a forma do improviso dependeria de acordos culturais e predisposições do público, reconhecendo a memória como atividade coletiva. Zumthor (2010), então, define improvisação como:

Em princípio, coincidência entre a produção e a transmissão de um texto: este, composto na performance, opõe-se àqueles compostos para ela. De fato, a improvisação não é jamais total; o texto produzido no ato, o é em virtude de normas culturais, e mesmo preestabelecidas. (ZUMTHOR, 2010, p. 254)

Segundo Havelock (1996), a oralidade é um contínuo entre produzir-se e perderse. É a efemeridade comunicativa que, no momento em que emerge, imediatamente deixa de existir como presença e passa a ser memória. Sendo que, depois de declamada, sai do âmbito da memória do poeta e alcança a dimensão de uma memória compartilhada. Daí uma forte relação de coexistência com a escrita. É a combinação que agrega potencialidades de

\footnotetext{
${ }^{4}$ As Lendas de Dandara e 15 Heroínas Negras.

5 Thaís Araújo, no programa Saia Justa do canal GNT - GloboSat - declama 5 poemas do livro 15 Heroínas Negras, de Jarid Arraes, durante o mês de novembro.

${ }^{6}$ Poeta Bráulo Bessa viralizou na Internet um vídeo declamando um poema sobre pessoas que brigam por motivos políticos e depois foi contratado para, semanalmente, declamar poesias no programa Encontro com Fátima Bernardes - Rede Globo.
} 
permanência, circulação e memorização com as dimensões da performance do corpo e da presença.

Acontece, como apresenta Zumthor (2010, p. 12), que a voz é um “instante sem duração". É efêmera e acaba quando se realiza. O que também aponta Ong (1990) referindose ao som, que só acontece quando deixa de existir. O que dificulta os processos analíticos, que nos impedem de voltar ao som para refleti-lo. Uma vez ouvido, ele termina. Torna-se passado.

Toda sensação ocorre no tempo, mas o som possui uma relação especial com ele, diferente da que existe em outros campos registrados na sensação humana. O som existe apenas quando está deixando de existir. Ele não é apenas perecível, mas é essencialmente evanescente e percebido como evanescente. Quando pronuncio a palavra "permanência", no momento em que chego a "-nência", "perma-" desapareceu e tem de desaparecer. (ONG, 1990, p. 32)

Essa relação entre oralidade e escrita, segundo Ong (1990), não cria uma "literatura oral", pois o termo literatura estaria ligado às noções de letra escrita. A produção de ficção pela oralidade configura uma outra categoria - "oratura", talvez. Ong (1990) não propõe esse conceito para as formas "puramente orais" de contação de histórias, mas destaca que não se pode tratar a produção oral da mesma forma que se entende as produções escritas as literárias. Tampouco produz-se uma hierarquização de materialidades, mas é preciso destacar que as especificidades das formas deixam ver sentidos distintos nos processos comunicacionais. Por isso, convocam métodos, posicionamentos e olhares diferentes entre si. Quando Ong sugere que o termo "literatura oral" parece incompatível, significa que precisamos considerar os conhecimentos escritos e orais a partir de suas características distintivas, que resultam em processos diversos.

No caso da poesia de cordel, percebemos que as materialidades se complementam. Na voz, no corpo e nos folhetos - ou livros, ou vídeos, ou redes sociais. De uma performance comunicativa, que contempla um certo grau de teatralização e que alcança a forma impressa e vendida, ainda que esteja, na maioria das vezes, fora do mercado editorial tradicional.

Nesse contexto, Ong (1990, p. 13) sugere que uma opção de abordagem para as produções orais seja a partir da ideia de "texto", "cuja raiz significa "tecer", é, em termos

\footnotetext{
7 "All sensation takes place in time, but sound has a special relationship to time unlike that of the other fields that register in human sensation. Sound exists only when it is going out of existence. It is not simply perishable but essentially evanescent, and it is sensed as evanescent, when I pronounce the word 'permanence', by the time I get to the '-nence', the 'perma-' is gone, and has to be gone." (ONG, 1990, p. 32)

${ }^{8}$ Conceito conflituoso por propor uma separação material das produções ficcionais. Trazido aqui apenas como uma referência, pois apesar da sua existência, ainda não tenho condições epistemológicas de tomar uma posição diante dele.
} 
absolutos, mais compatível etimologicamente com a enunciação oral do que "literatura", que etimologicamente se refere a letras (literae) do alfabeto." 9 Tal compreensão dialoga, inclusive, com a nossa concepção de textualidade como a tessitura de elementos significativos, articulados por atores em diálogo em um determinado tempo e espaço.

Essa ideia de uma literatura oral também é tratada por Zumthor (2010). Ele considera que haja uma “imbricação indestrinçável do 'literário' e do 'não literário', misturada com o oral e o escrito" (p. 23). Este também considera que haja uma complementaridade entre oralidade e escrita nas sociedades contemporâneas, às quais acrescentamos as formas digitais e online de produção, registro e circulação de conteúdos. As formas e materialidades coexistem na produção de informações e os usos são aplicados de acordo com a necessidade que os atores identificam.

As potencialidades de cada meio se combinam e encontramos, como já mencionado, vídeos e áudios na Internet com performances poéticas. Obviamente, esses meios têm especificidades de sentidos, mas sua existência não se sobrepõe às formas préexistentes, tampouco se pode valorar qual das materialidades seria melhor, mais original ou pura. "Em cada época coexistem e colaboram homens da oralidade e homens da escrita" (ZUMTHOR, 2010, p. 35). Os indivíduos escolhem, diante dos meios disponíveis, aquele que melhor se adequa às suas necessidades do momento, inclusive considerando transformações culturais que se dão a partir da presença de novos dispositivos sociotécnicos.

Há que se perceber ainda que, mesmo diante da coexistência entre as materialidades que se combinam, não podemos transpor os modos de análise de fenômenos escritos para os fenômenos orais. É comum que, para o estudo de declamações, poesias orais e performances, haja uma transcrição do texto. Isso impede que sejam levados em consideração os elementos da obra, que foram definidos por Zumthor $(2014,2010)$.

Observamos, então, o que Ong (1990) chama de oralidade secundária, ou seja, aquela mediada por dispositivos técnicos, é também o que Zumthor (2010) classifica como uma oralidade mecanicamente mediatizada. A oralidade secundária definida por Zumthor (2010) está relacionada à coexistência com a escrita, podendo funcionar como mista influência externa - ou segunda - que se recompõe, tendo a escrita como predominante na prática e no imaginário. No caso da oralidade secundária, a escrita seria uma forma de "dissimular" as características da poesia da voz tratadas como "fraquezas", que são

9 "Text, from a root meaning 'to weave', is, in absolute terms, more compatible etymologically with oral utterance than is 'literature' which refers to letters etymologically/(literae) of the alphabet." (ONG, 2010, p. 13) 
justamente aquelas relacionadas à efemeridade e ao alcance restrito a um espaço físico delimitado.

Como já mencionado, a poesia de cordel existe combinando formas orais e escritas, circulando nas feiras, impressas em folhetos, em páginas da Internet, em grupos de Whatsapp. Deste modo, mesmo escrita, a poesia de cordel guarda marcas da oralidade, sua forma básica, que dá as referências para o processo criativo. "Assim são esses textos lidos com os olhos: sentimos intensamente que uma voz vibrava originalmente em sua escritura e que eles exigem ser pronunciados"(ZUMTHOR, 2010, p.39). Que mesmo sendo feito acompanhado de papel, é cantado como experimentação dos versos para caberem nas rimas e na métrica adequada.

A oralidade como modo de comunicação e troca de conhecimentos é tratada por Zumthor (2010) como uma forma que se estabelece ao "falar", apoderada pelos públicos na ação de escutar. Essa comunicação teria uma função "exteriorizadora", assegurando uma circulação desses conhecimentos por diversos modos, entre eles a poesia oral.

Marcadamente conotativo, ligado a todos os jogos de linguagem cuja combinação forma o vínculo social, ele [o discurso de comunicação] deve sua legitimidade e sua força persuasiva muito mais ao testemunho que constitui do que ao que expõe, de modo que o critério de verdade desaparece em benefício de um outro muito mais fluido: a comunicação é memória dócil, flexível, maleável, nômade e (graças à presença dos corpos) globalizadora. (ZUMTHOR, 2010, p. 34)

Zumthor (2010) chama de oral "toda comunicação poética em que, pelo menos, transmissão e recepção passem pela voz e pelo ouvido" (p. 32). Trata-se de uma poesia com regras de musicalidade que coloca em relações de trocas de sentidos e afetos os atores que se comunicam por este processo. As potencialidades desta poesia se realizam na performance.

\section{CONSIDERAÇÕES}

Este trabalho traz uma síntese da reflexão sobre os aspectos de oralidade que compõem conceitualmente o universo poético do cordel. Não são conceitos definidores, mas discussões que nos ajudam a pensar sobre os elementos da performance que compõem uma textualidade baseada em memórias e tradições, que consideram as materialidades como produtoras de sentidos, muito mais do que suportes.

Seja no improviso, nas declamações memorizadas ou lidas, nas leituras individuais, nos formatos online que pressupõem compartilhamentos, impressa em folhetos ou livros, a poesia de cordel tem formas decorrentes da cantoria. Com métrica, rima, ritmo. Com 
imagens - xilogravuras, cenários de feiras, figurinos de poetas, movimento de corpos, imagens de palavras - e sons - da declamação, das violas, dos vendedores, dos consumidores das feiras, das pessoas nos bares. O cordel não termina em uma definição e nos escapa em cada rearranjo.

Quando dizemos que o cordel vai além do suporte, não significa dizer que eles não importam para o entendimento desta poesia. Pelo contrário. Assim, consideramos que as materialidades são definidoras e que os sentidos adquirem contornos distintos ao transitarem em diferentes espaços. O que afirmamos com isso é que a forma não define o conceito de cordel, ainda que implique em seus sentidos e afetações. Nosso intuito e apontamento metodológico não despreza formas, materialidades, contornos e afetações, mas em vez disso coloca-os em relação com os demais elementos, como os atores, os signos, os embates político-culturais, com as tradições e memórias que também constituem sua textualidade.

O que nos ajuda a compreender o fenômeno é o conjunto de sentidos que dele emerge. Os diálogos possíveis entre formas, materialidades, ambientes, atores, tempos. Pela produção da presença ou mediada por equipamentos técnicos. Pelos corpos em performance construindo narrativas, reconfigurando sentidos. Convocando universos simbólicos e abrindo constantemente, a cada contato, novas questões.

Das discussões e diálogos aqui levantados, abrem-se outras reflexões necessárias para pensarmos as dimensões de performance e de presença no cordel: as já apontadas questões de autoria coletiva e plural - considerando que o cordel emerge na relação entre poetas e ouvintes; e as consequentes dimensões estéticas da performance poética do cordel em seus espaços de presença. Estas são brechas que este trabalho anuncia como sua continuidade, destacadas dentre a ampla diversidade de inquietações produzidas pelo fenômeno do cordel e suas manifestações.

\section{REFERÊNCIAS}

ABRIL, Gonzalo. Cultura visual: de la semiótica a la política. Madri: Plaza y Valdés, 2014.

BAUMAN, Richard; BRIGGS, Charles. Poética e performance como perspectivas críticas sobre linguagem e a vida social. Tradução de Vânia Cardoso. Ilha Revista de Antropologia, Florianópolis, v. 8, n. 1, p. $2,2006$.

CARVALHO, Gilmar de. Cordel, cordão, coração. Revista do GELNE Fortaleza: UFC, v. 4, p. 285292, 2002.

Patativa Poeta Pássaro do Assaré. Fortaleza: Omni Editora, 2002a. 
CARVALHO, Gislene. BARBOSA, Rafael. MULLER, Leandro. Crises como fraturas no tempo: o cordel e o mercado editorial. In.: MANNA, Nuno. VALE, Flávio. BERTOL, Rachel. MAIA, Jussara. Catástrofes e crises do tempo: Historicidades dos processos Comunicacionais. Belo Horizonte: Selo PPGCOM, 2020.

FONSECA, Maria Gislene Carvalho. Novelo de Verso: fios de memória, tradição e performance tecendo a poesia de cordel. [Tese de doutorado] Belo Horizonte: UFMG, 2019.

GUMBRECHT, Hans Ulrich. Produção de presença. Rio de Janeiro: Contracampo, 2010.

HAVELOCK, Eric. A revolução da escrita na Grécia e suas consequências culturais. Rio de Janeiro: Paz e Terra, 1996

ONG, Walter. Orality and Literacy: The tecnologizing of the word. London: Routledge, 1990.

ZUMTHOR, Paul. Performance, Recepção, Leitura. São Paulo: Cosac Naify, 2014.

Introdução à poesia oral. Belo Horizonte: UFMG, 2010.

Professora do Departamento de Jornalismo e do Programa de Pós-graduação em Comunicação Social da Universidade Federal de Ouro Preto. Doutora em Comunicação Social pela Universidade Federal de Minas Gerais. Estágio pós-doutoral realizado no mesmo programa.

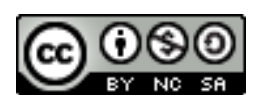

Esta obra está licenciada com uma Licença

Creative Commons Atribuição-NãoComercial-CompartilhaIgual 4.0 Internacional 